\title{
ANGIOGRAPHIC PROFILE IN WOMEN WITH CORONARY ARTERY DISEASE
}

\author{
Manoj Ravi ${ }^{1}$, Nisha Narendran ${ }^{2}$
}

${ }_{1}^{1}$ Associate Professor, Department of Cardiology, Jubilee Mission Medical College, Thrissur, Kerala, India. ${ }^{2}$ Associate Professor, Department of Paediatrics, Government Medical College, Thrissur, Kerala, India.

\section{BACKGROUND}

\section{ABSTRACT}

Coronary artery disease is the leading cause of morbidity and mortality among women as well as men in the industrialised world. Women represent 60 percent of those over the age of 65 years in the United States and more women than men have died of cardiovascular disease. Women and men with Acute Coronary Syndromes (ACS) have been found to have different clinical profiles and presentation with a smaller percentage of women than men presenting with ST-elevation MI, but more presenting with unstable angina. Women are more likely to die of first myocardial infarction, experience more long-term disability and have more comorbidities as presentations is later in life. Women also are less likely to undergo angioplasty or bypass surgery. Fewer women receive cardiac rehabilitation and medications. Hence the purpose of the study was to analyse the angiographile profile in relation to clinical presentation and risk factors.

Aims and Objectives- To analyse the angiographic findings in relation to clinical presentation and risk factors.

\section{MATERIALS AND METHODS}

Female patients with STEMI, NSTEMI or chronic stable angina without significant comorbidities were studied after Institutional Committee approval and informed consent from subjects and results were analysed.

\section{RESULTS}

Of the 140 patients studied, $85 \%$ belonged to post-menopausal age and the mean age of patients was $54.19+/-9.89$ years. $68 \%$ had angiographic evidence of coronary artery disease, of which $48 \%$ had significant coronary artery disease. LAD (41\%) was the commonest vessel and single vessel disease (39\%) predominated among significant CAD cases. The relationship between diabetes $(\mathrm{p}=0.009), \mathrm{BMI}>/=25(\mathrm{p}=0.007)$, family history of premature CAD $(\mathrm{p}=0.006)$, total cholesterol $>/=200(\mathrm{p}=0.011), \mathrm{LDL}>/=100$ $(\mathrm{p}=0.006)$ and $\mathrm{HDL}</=40(\mathrm{p}=0.009)$ were found to be statistically significant in the study.

\section{CONCLUSION}

The incidence of coronary artery disease is high in postmenopausal women as compared to premenopausal women. Women with acute coronary syndromes present more with unstable angina/ NSTEMI. Women are less likely to present with the syndrome associated with occlusive thrombus, that is with infarction with ST elevation.

\section{KEY WORDS}

Angina, Coronary Angiography, Coronary Artery Disease, NTSEMI, Risk Factors, STEMI, Women.

HOW TO CITE THIS ARTICLE: Ravi M, Narendran N. Angiographic profile in women with coronary artery disease. J. Evolution Med. Dent. Sci. 2018;7(41):4445-4449, DOI: $10.14260 /$ jemds/2018/992

\section{BACKGROUND}

Coronary artery disease is the leading cause of morbidity and mortality among women as well as men in the industrialised world. Women represent 60 percent of those over the age of 65 years in the United States $(1)$ and more women than men have died of cardiovascular disease. Women and men with Acute Coronary Syndromes (ACS) have been found to have different clinical profiles and presentation with a smaller percentage of women than men presenting with ST-elevation MI, but more presenting with unstable angina. Women are more likely to die of first myocardial infarction, experience more long-term disability and have more comorbidities as presentation is later in life. $(2,3,4)$ Women also are less likely to undergo angioplasty or bypass surgery.

'Financial or Other Competing Interest': None.

Submission 12-09-2018, Peer Review 24-09-2018,

Acceptance 27-09-2018, Published 08-10-2018.

Corresponding Author:

Dr. Manoj Ravi,

Associate Professor, Department of Cardiology,

Jubilee Mission Medical College, Thrissur-680005,

Kerala, India.

E-mail:nnped@yahoo.com

DOI: $10.14260 /$ jemds $/ 2018 / 992$
Fewer women receive cardiac rehabilitation and medications.(5) Hence, the purpose of the study was to analyse the clinical and risk factor profile of women admitted with CAD and their angiographic correlation.

\section{Aims and Objectives}

To analyse the angiographic findings in relation to clinical presentation and risk factors.

\section{MATERIALS AND METHODS}

Female patients with STEMI, NSTEMI or chronic stable angina without significant comorbidities were studied after Institutional Committee approval and informed consent from subjects and results were analysed.

Type of Study-Prospective observational study.

Study Setting- Lokmanya Tilak Municipal Medical College, Sion, Tertiary Care Hospital in Mumbai.

Study Period- Jan 2005 to July 2006

Sample Size- The sample size as considering the prevalence of CAD in women in India was fixed as 140 patients. 


\section{Inclusion Criteria}

1. Female patients with acute ST elevation myocardial infarction by standard definition.

a) Characteristic chest pain suggestive of ischaemia for prolonged period ( $>30$ mins). OR

b) Evolutionary changes in ECG showing ST elevation of at least $1 \mathrm{~mm}$ in two contiguous limb leads or $2 \mathrm{~mm}$ in two contiguous chest/ precordial leads. OR

c) Characteristic rise and fall of enzymes (CK-MB and Troponins) suggestive of myonecrosis.

2. Female patients presenting with unstable angina/NSTEMI. Unstable angina is defined as angina with at least one of the following:

a) Occurring at rest (or minimal exertion) and usually lasting more than 20 mins.

b) Being severe and described as frank pain and of new onset (i.e. within a month).

c) Occurring after a crescendo pattern.

Patients with elevated biomarkers of cardiac necrosis (CPK MB, Troponin) are diagnosed as having NSTEMI.

3. Female patients with chronic stable angina.

a) Typical angina.

1. Substernal chest discomfort with a characteristic quality and duration that is provoked by exertion or emotional stress, and

2. Relieved by rest or nitroglycerine.

b) Atypical angina (probable) meeting 2 of the above characteristics.

c) Who had other standard indications for coronary angiography.

\section{Exclusion Criteria}

1. Patients with serious comorbidities in whom the risks of the procedure outweighs the benefit of the procedure.

2. Patients with non-cardiac chest pain (meets $<1$ of the typical angina features).

3. Patients not willing for revascularisation.

\section{Method}

The study was done after approval by the Institutional Research and Ethics Committee. The subjects were included after getting informed consent and demographic data. Clinical laboratory and angiographic profile was analysed using a proforma. Coronary angiography was performed on Siemens Image Intensifier based Cathlab System in the department. It was performed in multiple projections by the Judkins technique using either femoral or transradial approach. Images were acquired on cine films and stored in Hicor system.

Angiograms were analysed from cine recording and reports were compared with QCA measurements for extent of stenosis. Presence, location and extent of CAD were noted. For the purpose of study, significant stenosis of CAD was defined as luminal stenosis more than $70 \%$. Patients with less than $70 \%$ luminal stenosis was defined as having minor lesions. Patients were classified as single vessel disease if only one vessel had significant stenosis, double vessel disease if two vessels were involved and triple vessel disease if 3 vessels were involved. If there was a significant left main disease, it was considered to have left main disease.

\section{Statistical Analysis}

Data was entered in Excel and analysed using SPSS version 10. Quantitative variables have been expressed as mean with their standard deviation. Qualitative variables have been described in percentages. Quantitative variables like BMI, HDL were dichotomised using appropriate cut-off values suggested for this population. Analysis of risk factors have been done using Chi-square test. Significance level was placed at $<0.05$.

\section{RESULTS}

140 subjects were included in the study-

1. The mean age of patients was $54.19+/-9.89$ years, maximum number of patients were $>60 \mathrm{yrs}$.

2. $21(15 \%)$ were premenopausal and rest $119(85 \%)$ were postmenopausal. $95(68 \%)$ patients had angiographic evidence of CAD, while coronary angiography was normal in $45(32 \%)$ patients.

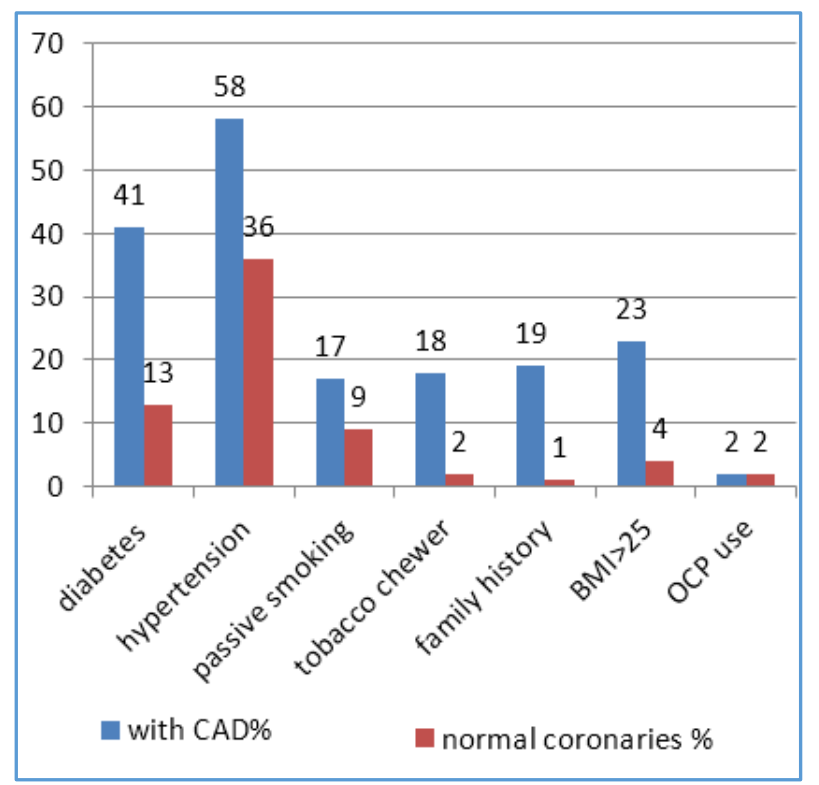

Figure 1. Risk Factor distribution in Patients with and without Angiographically proven CAD

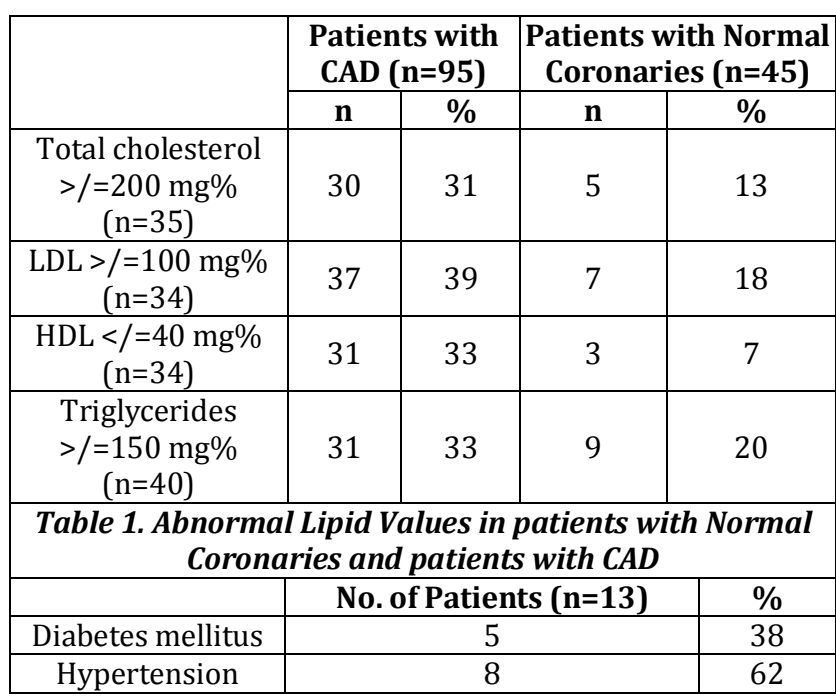




\begin{tabular}{|c|c|c|}
\hline Passive smoking & 4 & 31 \\
\hline Tobacco chewing & 3 & 23 \\
\hline $\begin{array}{l}\text { Family history of } \\
\text { premature CAD }\end{array}$ & 4 & 31 \\
\hline $\mathrm{BMI}>/=25$ & 1 & 8 \\
\hline $\begin{array}{l}\text { Total cholesterol } \\
>/=200\end{array}$ & 5 & 38 \\
\hline LDL $>/=150$ & 6 & 46 \\
\hline OCP use & 2 & 16 \\
\hline \multicolumn{3}{|c|}{$\begin{array}{c}\text { Table 2. Risk Factor distribution in Premenopausal } \\
\text { Women with Angiographically proven CAD }\end{array}$} \\
\hline
\end{tabular}

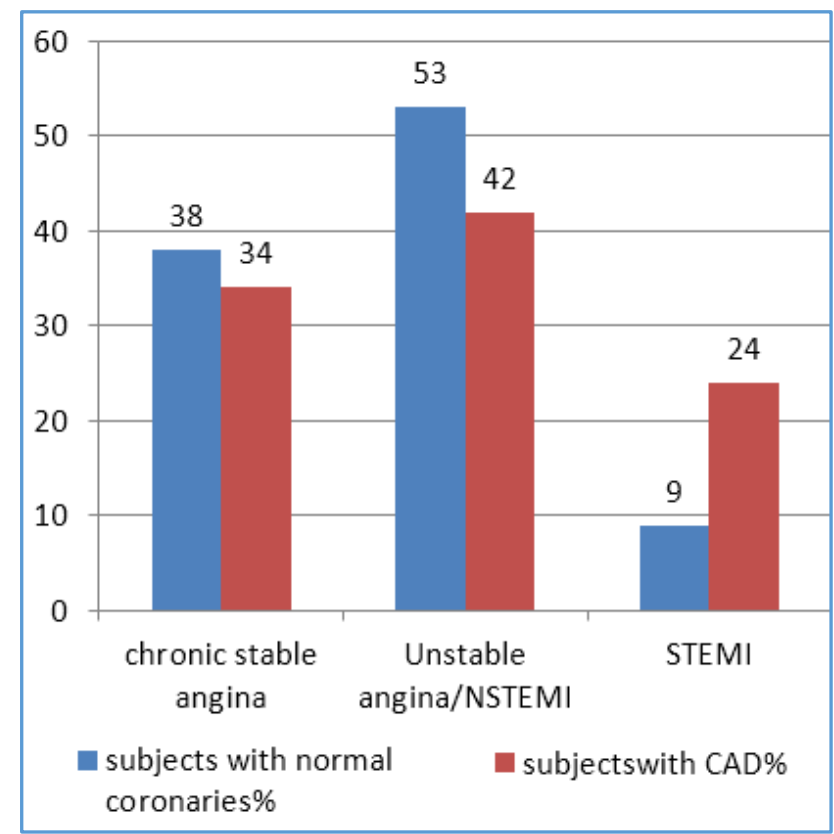

Figure 2. Type of Presentation in patients with normal Coronaries and patients with CAD

\begin{tabular}{|c|c|c|}
\hline Coronary Vessel & No. (n=192) & \% \\
\hline LAD & 78 & 41 \\
\hline LCX & 50 & 26 \\
\hline RCA & 56 & 29 \\
\hline Left Main & 8 & 4 \\
\hline \multicolumn{2}{|c|}{ Table 3. Distribution of Lesions in Coronary Vessels } \\
\hline
\end{tabular}

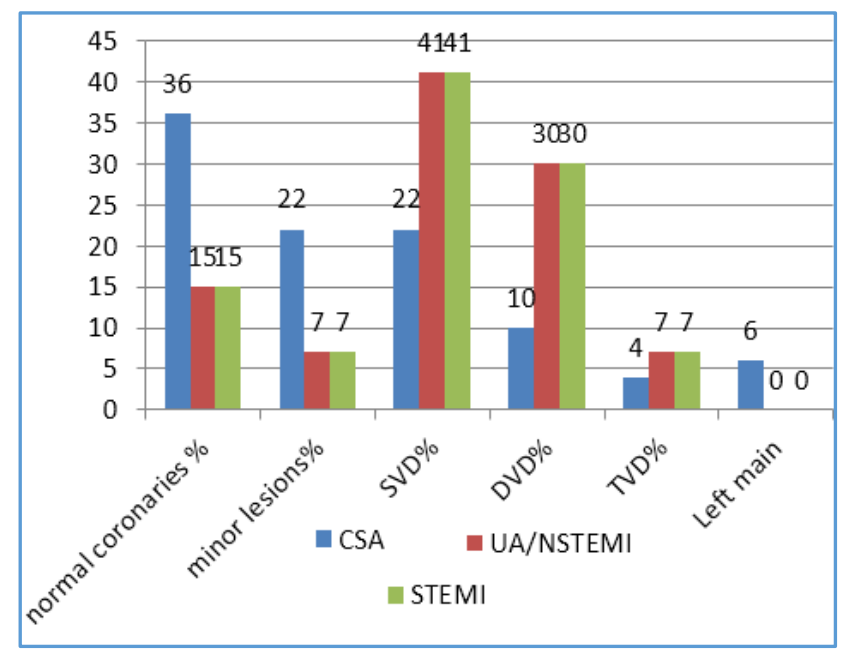

Figure 3. Relation of Type of Presentation with Type of Coronary Lesion

\begin{tabular}{|c|c|c|c|c|}
\hline \multirow{2}{*}{ Risk Factor } & \multirow{2}{*}{$\begin{array}{c}\text { Total } \\
\text { No. }\end{array}$} & \multicolumn{2}{|c|}{ CAD } & \multirow{2}{*}{ P value } \\
\cline { 3 - 4 } & 45 & 39 & 6 & 0.009 \\
\hline Diabetes & 45 & Absent & \\
\hline
\end{tabular}

\begin{tabular}{|c|c|c|c|c|}
\hline Without diabetes & 95 & 56 & 39 & \multirow{3}{*}{0.058} \\
\hline Hypertension & 71 & 55 & 16 & \\
\hline Without hypertension & 69 & 40 & 29 & \\
\hline Passive smoking & 20 & 16 & 4 & \multirow[b]{2}{*}{0.301} \\
\hline $\begin{array}{l}\text { Without passive } \\
\text { smoking }\end{array}$ & 120 & 79 & 41 & \\
\hline $\begin{array}{l}\text { Family history of } \\
\text { premature CAD }\end{array}$ & 19 & 18 & 1 & 0.006 \\
\hline $\begin{array}{c}\text { Without family history } \\
\text { of premature CAD }\end{array}$ & 121 & 77 & 44 & \\
\hline Tobacco chewing & 19 & 17 & 2 & \multirow[b]{2}{*}{0.304} \\
\hline $\begin{array}{c}\text { Without tobacco } \\
\text { chewing }\end{array}$ & 121 & 78 & 43 & \\
\hline $\mathrm{BMI}>/=25$ & 24 & 22 & 2 & \multirow{2}{*}{0.007} \\
\hline $\mathrm{BMI}</=25$ & 116 & 73 & 43 & \\
\hline \begin{tabular}{|c} 
Total cholesterol $>/=$ \\
200 \\
\end{tabular} & 35 & 30 & 5 & \multirow{2}{*}{0.0114} \\
\hline $\begin{array}{c}\text { Total cholesterol }</= \\
200\end{array}$ & 105 & 65 & 40 & \\
\hline LDL $>/=100$ & 44 & 37 & 7 & \multirow{2}{*}{0.006} \\
\hline $\mathrm{LDL}</=100$ & 96 & 58 & 38 & \\
\hline $\mathrm{HDL}>/=40$ & 33 & 31 & 3 & \multirow{2}{*}{0.009} \\
\hline $\mathrm{HDL}</=40$ & 107 & 64 & 42 & \\
\hline $\mathrm{TG}>/=150$ & 40 & 31 & 9 & \multirow{2}{*}{0.161} \\
\hline $\mathrm{TG}</=150$ & 100 & 64 & 36 & \\
\hline Postmenopausal & 119 & 82 & 37 & \multirow{2}{*}{0.613} \\
\hline Premenopausal & 21 & 13 & 8 & \\
\hline Tablo 1 Doti & & & & \\
\hline
\end{tabular}

\section{DISCUSSION}

This study was done to assess the clinical and risk factor profile of women admitted with coronary artery disease and to analyse the angiographic findings in relation to risk factors.

The mean age of affected group in the study was $54.19+/-$ 9.89 years, maximum patients being in $>60$ years' age group. Youngest patient was 30 years and oldest was 75 . The mean age is in par with findings from many other studies. Women are about 10 years older than men at first manifestation of CAD in the absence of other risk factors. $(6,7,8,9)$

$119(85 \%)$ patients in our study population were postmenopausal age group.

Out of 140 patients 45 (32\%) had normal coronaries, while $95(68 \%)$ had coronary lesions on angiography. This is similar to the $30.7 \%$ normal coronaries as concluded by Dave $\mathrm{TH}$ et al after analysing a similar set of 101 female patients.(10) Analysis of coronary angiograms from a large series of women enrolled in the WISE study who had suspected ischaemic chest pain, 34\% had no detectable coronary lesion. This can be attributed to atypical chest pain in women.

Out of 21 premenopausal females $13(62 \%)$ had evidence of coronary artery disease on angiography, of which $48 \%$ had significant coronary artery disease. In a study of women under the age of 45 years referred for coronary angiography, De $\mathrm{S}$ et al found that $65 \%$ had completely normal coronary arteries.(11)

Of the 323 women enrolled in the pilot phase of Women's Ischaemia Syndrome Evaluation study who had suspected ischaemic chest pain, age, hypertension, diabetes mellitus, prior myocardial infarction, current hormone replacement therapy and unstable angina were all significant independent predictors of significant disease.(12) 
The prevalence of cardiac risk factors and the rate of angiographically critical coronary artery disease in women under the age of 45 years for the first time evaluation of chest pain was studied by De S et al.(11) When compared to people without angiographic evidence of CAD, women with CAD had a higher prevalence of dyslipidaemia $(72 \%$ versus $47 \%$, $\mathrm{p}=0.002)$, diabetes $(29 \%$ versus $9 \%, \mathrm{p}<0.001)$ and smoking (67\% versus $50 \%, p=0.03$ ). The association of risk factors with angiographically proven coronary artery disease was analysed in this study. The relationship between diabetes $(\mathrm{p}=0.009), \quad$ BMI $>/=25(\mathrm{p}=0.007)$, family history of premature $\operatorname{CAD}(\mathrm{p}=0.006)$, total cholesterol $>/=200$ $(\mathrm{p}=0.011), \mathrm{LDL}>/=100(\mathrm{p}=0.006)$ and $\mathrm{HDL}</=40$ $(p=0.009)$ were found to be statistically significant.

In the study by De $S$ et al to determine the rate of angiographically critical coronary artery disease in women under the age of 45 years who sent for the first time evaluation of chest pain requiring cardiac catheterisation, 52 percent patients with significant coronary artery disease had single vessel disease. In the present study, single vessel disease was commonest followed by double vessel disease as well.

Left anterior descending (41\%) was the most common vessel followed by right coronary artery (29\%). The LAD was the most commonly affected as per study by Pinto RJ et al as well.(13) Among patients with TVD, 75\% (12 out of 16) presented with unstable angina/ STEMI. This relation was found to be statistically significant.

\section{CONCLUSION}

The incidence of coronary artery disease is high in postmenopausal women as compared to premenopausal women.

Women with acute coronary syndromes present more with unstable angina/ NSTEMI. Women are less likely to present with the syndrome associated with occlusive thrombus - that is with infarction with ST elevation.

A substantial percentage of women presenting with symptoms of angina pain have angiographically normal coronaries suggesting that angina as a presenting symptom is less predictive of occlusive coronary artery disease in women.

Among premenopausal women with coronary artery disease, hypertension and low HDL are the most common risk factors.

In women with coronary artery disease, majority has a single vessel disease. Most involved vessel is left anterior descending artery.

Diabetes mellitus and body mass index more than or equal to 25 are significantly associated with angiographically proven coronary artery disease in women.

Family history of premature coronary artery disease is an important risk factor in women.

Elevated total cholesterol and LDL and decreased HDL is significantly associated with coronary artery disease in women. However, relation with elevated triglycerides is not statistically significant. Women with triple vessel disease are more likely to present with unstable angina. Triple vessel disease is more common in women with diabetes mellitus, elevated total cholesterol, elevated LDL and elevated triglyceride levels.

\section{Limitations of the Study}

This is an observational study and controls were not included. Men were not included in the study for comparison between genders. Sample size being small, broad conclusions cannot be made from the study. The effect of various risk factors on disease progression was not studied as no followup was done as part of the study. Premenopausal patients formed only a small group in the study.

\section{ACKNOWLEDGEMENT}

Dr. A U Mahajan MD DM (Cardiology) Professor, Department Of Cardiology Lokmanya Tilak Memorial Govt Municipal Medical College, Sion, Mumbai, Dr. Zinia T. Nujum, Additional Professor, Department of Community Medicine, Govt. Medical College, Kollam.

\section{REFERENCES}

[1] Mark DB. Sex bias in cardiovascular care: Should women be treated more like men? JAMA 2000;283(5):659-61.

[2] Chiriboga DE, Yarzebski J, Goldberg RJ, et al. A community-wide perspective of gender differences and temporal trends in the use of diagnostic and revascularisation procedures for acute myocardial infarction. Am J Cardiol 1993;71(4):268-73.

[3] Fiebach NH, Viscoli CM, Horwitz RI. Differences between women and men in survival after myocardial infarction: Biology or methodology? JAMA 1990;263(8):1092-6.

[4] Robinson K, Conroy RM, Mulachy R, et al. Risk factors and in-hospital course of first episode of myocardial infarction or acute coronary insufficiency in women. J Am Coll Cardiol 1988;11(5):932-6.

[5] He J, Klag MJ, Whelton PK, et al. Short- and long-term prognosis after acute myocardial infarction in Chinese men and women. Am J Epidemiol 1994;139(7):693703.

[6] Dittrich H, Gilpin E, Nicod P, et al. Acute myocardial infarction in women: influence of gender on mortality and prognostic variables. Am J Cardiol 1988;62(1):1-7.

[7] Stone GW, Grines CL, Browne KF, et al. Comparison of in-hospital outcome in men versus women treated by either thrombolytic therapy or primary coronary angioplasty for acute myocardial infarction. Am J Cardiol 1995;75(15):987-92.

[8] Hochman JS, Tamis JE, Thompson TD, et al. Sex, clinical presentation and outcome in patients with acute coronary syndromes. Global use of strategies to open occluded coronary arteries in acute coronary syndromes IIb investigators. N Engl J Med 1999;341(4):226-32.

[9] Rosengren A, Wallentin L, Gitt KA, et al. Sex, age and clinical presentation of acute coronary syndromes. European Heart Journal 2004;25(8):663-70.

[10] Dave TH, Wasir HS, Prabhakaran D, et al. Profile of coronary artery disease in Indian women: correlation of clinical, non-invasive and coronary angiographic findings. Indian Heart J 1991;43(1):25-9. 
[11] De S, Searles G, Haddad H. The prevalence of cardiac risk factors in women 45 years of age or younger undergoing angiography for evaluation of undiagnosed chest pain. Can J Cardiol 2002;18(9):9458.

[12] Sharaf BL, Pepine CJ, Kerensky RA, et al. Detailed angiographic analysis of women with suspected ischemic chest pain (pilot phase data from the NHLBIsponsored Women's Ischemia Syndrome Evaluation (WISE) Study Angiographic Core Laboratory). Am J Cardiol 2001;87(8):937-41:A3.
[13] Pinto RJ, Bhagawat AR, Loya YS, et al. Coronary artery disease in premenopausal Indian women: risk factors and angiographic profile. Indian Heart J 1992;44(2):99-101. 